\title{
A PARTICIPAÇÃo COMUNITÁRIA NO SISTEMA ÚNICO DE SAÚDE: REVISÃo INTEGRATIVA DA LITERATURA
}

\section{Community participation in the Unified Health System: an integrative literature review \\ La participación de la comunidad en el Sistema Único de Salud: revisión integrativa de la literatura}

\author{
Violeta Campolina Fernandes \\ Universidade Estadual Paulista - UNESP - Botucatu (SP) - Brasil \\ Regina Stella Spagnuolo \\ Universidade Estadual Paulista - UNESP - Botucatu (SP) - Brasil \\ Jamile Gabriela Bronzato Bassetto \\ Universidade Estadual Paulista - UNESP - Botucatu (SP) - Brasil
}

\section{RESUMO}

Objetivo: Revisar, na literatura, a participação comunitária no Sistema Único de Saúde. Métodos: A busca bibliográfica foi realizada por três examinadores independentes nas bases de dados eletrônicas Banco de Dados de Enfermagem (BDENF), Literatura Latino-Americana e do Caribe em Ciências da Saúde (LILACS) e (Scientific Electronic Library Online (SciELO), com os descritores: "participação comunitária", "Sistema Único de Saúde" e "saúde". Os dados foram coletados de agosto a outubro de 2016, tendo os seguintes critérios de elegibilidade: publicações completas em periódicos científicos publicadas entre o período de 1988 e 2016, sem restrição de idioma. Resultados: Após aplicados os critérios de elegibilidade e exclusão, restaram 28 artigos, que desvelaram-se em duas categorias temáticas, a saber: "A participação comunitária na Atenção Primária à Saúde" e "Os diferentes caminhos da participação comunitária". Conclusão: O estudo deu visibilidade à produção científica acerca da participação comunitária e pôde-se inferir que apresentou crescente incorporação prática em diferentes campos da saúde coletiva, com destaque às Unidades de Saúde da Família e aos Conselhos de Saúde.

Descritores: Participação Comunitária; Sistema Único de Saúde; Políticas Públicas; Saúde Pública; Conselhos de Saúde; Atenção Primária à Saúde.

\section{ABSTRACT}

Objective: To review, in the literature, the community participation in the Unified Health System. Methods: The literature search was performed by three independent researchers in the electronic databases Brazilian Nursing Database (BDENF), Latin American and Caribbean Center on Health Sciences Information (LILACS), and Scientific Electronic Library Online (SCIELO), using the keywords: "community participation", "Unified Health System" and "health". Data was collected from August to October 2016, with the following eligibility criteria: full-text publications released in national journals in the period from 1988 to 2016, with no language restrictions. Results: After applying the eligibility and exclusion criteria, 28 articles remained, which addressed two thematic categories, namely, "Community participation in Primary Health Care" and "The different paths of community participation". Conclusion: The study gave visibility to the scientific literature about the community participation and it can be inferred that it showed increased practical incorporation into different fields of collective health, with emphasis on the Family Health Units and Municipal Health Councils.

Descriptors: Community Participation; Unified Health System; Public Policies; Public Health; Health Councils; Primary Health Care.

RESUMEN

Objetivo: Revisar en la literatura la participación de la comunidad en el Sistema Único de Salud. Métodos: La búsqueda bibliográfica ha sido realizada por tres examinadores independientes en las bases de datos electrónicas BDENF (Banco de Datos de Enfermería), LILACS (Literatura Latino-Americana y del Caribe en Ciencias de la Salud) y SciELO (Scientific Electronic Library Online) con los descriptores: "Participación comunitaria", "Sistema Único de Salud" y "Salud". Se recogieron los datos entre agosto y octubre de 2016 con los siguientes criterios de elegibilidad: publicaciones completas en periódicos cientificos entre 1988 y 2016 sin restricciones de idiomas. Resultados: Tras 
la aplicación de los criterios de elegibilidad y exclusión restaron 28 artículos que revelaron dos categorías temáticas: "La participación de la comunidad en la Atención Primaria de Salud" y "Los distintos caminos de la participación de la comunidad". Conclusión: El estudio ha dado visibilidad para la producción cientifica sobre la participación de la comunidad y se puede inferir que la misma presentó mayor incorporación práctica en distintos campos de la salud colectiva en especial en las Unidades de Salud de la Familia y en los Consejos de Salud.

Descriptores: Participación Comunitaria; Sistema Único de Salud; Politicas Públicas; Salud Pública; Consejos de Salud; Atención Primaria de Salud.

\section{INTRODUÇÃO}

A participação comunitária no âmbito da saúde coletiva foi difundida nos países em desenvolvimento no início da década de 70, sendo considerada estratégia essencial para melhorar o acesso aos serviços de saúde nos setores mais vulneráveis da população. Este fato legitimou-se em 1978, na Conferência Internacional de Atenção Primária à Saúde, realizada em Alma Ata, União Soviética, sobre Cuidados de Saúde Primários, com o objetivo de alcançar, até o ano 2000, saúde para todos ${ }^{(1)}$.

Antes da criação do Sistema Único de Saúde (SUS) e com a necessidade de ampliar a cobertura à população, foram criadas, em 1983, as Ações Integradas de Saúde (AIS), com objetivo de diminuir a exclusão dos cidadãos à saúde ${ }^{(2)}$. Nesse cenário, surgiu a descentralização do planejamento e administração, sendo criadas comissões nos níveis estadual, regional e municipal, havendo uma maior aproximação dos usuários aos serviços ${ }^{(2)}$.

Portanto, a participação comunitária no Brasil antecede à criação do SUS, iniciando-se com os movimentos sociais e a Reforma Sanitária nas décadas de 70 e 80, tendo como lema "saúde é democracia"(3). Esses movimentos sociais foram liderados por intelectuais, profissionais de saúde e militantes de sindicatos, ultrapassando os limites da igreja progressista, pois representavam a sociedade civil organizada na luta pela redemocratização da saúde.

Esse fato culminou na $8^{a}$ Conferência Nacional de Saúde, em 1986, um grande marco na nossa história, já que, pela primeira vez, a população pôde participar dessas discussões e suas propostas foram contempladas na Constituição Federal de 1988, na Lei no 8.080/90 e na Lei no 8.142/90, que são consideradas as Leis Orgânicas da Saúde ${ }^{(4-7)}$.

No Brasil, a participação da comunidade é preconizada em todas as esferas de governo e nos conselhos de saúde, sendo estabelecida como diretriz para as ações dos serviços públicos de saúde, juntamente com a descentralização da gestão e o atendimento integral ${ }^{(5-7)}$.

A participação corresponde a um processo ativo de ressocialização, em que o indivíduo adquire uma cultura cívica própria. Assim, em uma sociedade democrática, que valoriza a interação e integração da participação comunitária, há uma tendência dos indivíduos se efetivarem como atores ativos com vistas à promoção de valores e interesses comuns, concretizando uma medida do exercício efetivo dos direitos de cidadania política ${ }^{(8)}$.

Nesse contexto, a promoção da saúde trabalha a mobilização comunitária ao romper o individualismo característico das sociedades modernas, fortalecer parcerias e atuar intersetorialmente a favor da corresponsabilização da saúde ${ }^{(9)}$.

Dessa forma, a participação apresenta-se relevante e tem influência no campo da saúde coletiva e nas políticas públicas em todos os níveis da federação, pois qualifica a gestão, amplia a equidade e o acesso aos serviços, preserva a universalidade e melhora a atenção à saúde ${ }^{(10)}$. Frente ao exposto, este estudo tem como objetivo revisar na literatura a participação comunitária no Sistema Único de Saúde.

\section{MÉTODOS}

Trata-se de estudo do tipo revisão integrativa da literatura, conforme os pressupostos de Ganong ${ }^{(11)}$, envolvendo seis passos: estabelecimento do problema da revisão, seleção da amostra, categorização dos estudos, análise dos resultados, apresentação e discussão dos resultados, e apresentação da revisão.

Para coleta de dados participaram três avaliadores independentes, na qual foram utilizados os bancos de dados Banco de Dados de Enfermagem (BDENF), Literatura Latino-Americana e do Caribe em Ciências da Saúde (LILACS) e Scientific Electronic Library Online (SciELO), com os descritores: "participação comunitária", "Sistema Único de Saúde" e "saúde" no período de agosto a outubro de 2016.

Adotaram-se os seguintes critérios de elegibilidade: publicações completas em periódicos científico, sem restrições de idiomas, e publicações compreendidas no período de 1988 a 2016. Os critérios de exclusão foram: artigos de revisão da literatura, dissertações, teses ou capítulos de livros, artigos que não abordassem a participação comunitária como tema principal e trabalhos repetidos entre as bases.

A amostra inicial contou com 240 artigos, sendo 223 encontrados na base de dados LILACS, oito na SciELO e nove na BDENF. Após serem aplicados os critérios de elegibilidade e exclusão, resultaram 28 artigos (figura 1). Para tanto, visando a 
sistematização dos dados, utilizou-se um instrumento de fichamento elaborado pelos autores, onde constou: título, ano, autores, objetivos e resultados.

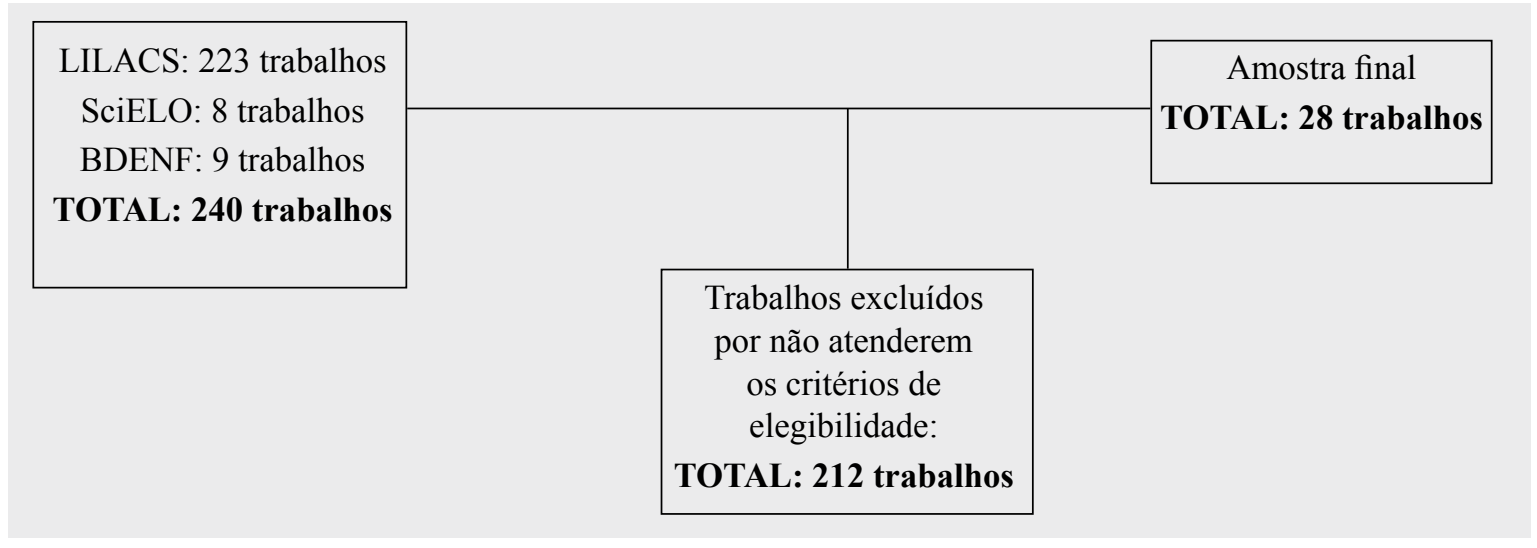

Figura 1 - Fluxograma da constituição da amostra que enfoca a participação comunitária no Sistema Único de Saúde, no período de 1988 a 2016.

A técnica de análise de conteúdo de Bardin ${ }^{(12)}$ foi utilizada como estratégia metodológica qualitativa para organizar sistematicamente a produção do conhecimento. A discussão foi alicerçada pelo referencial teórico da "Teoria da Democracia Participativa"(13,14).

\section{RESULTADOS}

Após a análise dos artigos encontrados, foram estudados 28 artigos, sendo 21 indexados na LILACS, 4 na SciELO e 3 na BDENF. Na composição da amostra, o maior volume de artigos foi publicado nos anos de 2011 (14,3\%) e 2012 (14,3\%), e a região das publicações mais representada foi a Sudeste (85,7\%). O método qualitativo foi predominante $(85,7 \%)$.

O quadro abaixo apresenta uma síntese dos 28 artigos $^{(15-29,31-43)}$ sobre participação comunitária que compuseram a amostra (Quadro I).

Quadro I - Características dos artigos selecionados descritos por autor, ano de publicação, objetivos e principais resultados.

\begin{tabular}{|c|c|c|c|}
\hline Autores & Ano & Objetivos & Resultados \\
\hline Fernandes, Monteiro ${ }^{(15)}$ & 1997 & $\begin{array}{l}\text { Incentivar o debate acerca da } \\
\text { reorganização das relações entre Estado e } \\
\text { sociedade civil por meio da apresentação } \\
\text { de uma experiência desenvolvida em um } \\
\text { posto de saúde gerido por entidade local. }\end{array}$ & $\begin{array}{l}\text { Apresenta as vantagens da } \\
\text { descentralização, autonomia, controle } \\
\text { social e desenvolvimento comunitário, } \\
\text { aproximando comunidade e equipes } \\
\text { de saúde na produção de ações mais } \\
\text { eficazes. }\end{array}$ \\
\hline Coura-Filho ${ }^{(16)}$ & 1998 & $\begin{array}{l}\text { Avaliar os indicadores específicos } \\
\text { da esquistossomose no programa de } \\
\text { controle em Taquaraçu de Minas, MG, } \\
\text { desenvolvido na rede básica de saúde } \\
\text { entre } 1985-1995 \text {, com a participação da } \\
\text { população na definição, gerenciamento e } \\
\text { execução das ações adotadas. }\end{array}$ & $\begin{array}{l}\text { A população de Taquaraçu de Minas, } \\
\text { entre } 1985 \text { e 1995, teve participação } \\
\text { ativa em ações de controle da } \\
\text { esquistossomose, promovendo } \\
\text { significativa redução da prevalência } \\
\text { e intensidade de infecção nessa } \\
\text { população. }\end{array}$ \\
\hline Vázques et al. ${ }^{(17)}$ & 2003 & $\begin{array}{l}\text { Analisar diferentes aspectos da } \\
\text { implementação das políticas de } \\
\text { participação social nos serviços de saúde } \\
\text { no Brasil. }\end{array}$ & $\begin{array}{l}\text { Houve pouca semelhança entre as } \\
\text { concepções dos usuários e líderes } \\
\text { comunitários sobre participação social } \\
\text { em relação ao enfoque das políticas } \\
\text { públicas de saúde. }\end{array}$ \\
\hline
\end{tabular}




\begin{tabular}{|c|c|c|c|}
\hline Arantes et al. ${ }^{(18)}$ & 2007 & $\begin{array}{l}\text { Analisar as concepções sobre controle } \\
\text { social e identificar as ações voltadas à } \\
\text { participação e ao controle social no SUS } \\
\text { de enfermeiras que atuam em unidades de } \\
\text { atenção básica. }\end{array}$ & $\begin{array}{l}\text { As enfermeiras relataram a realização } \\
\text { de ações voltadas à participação } \\
\text { social, como convidar a população } \\
\text { e funcionários a participarem dos } \\
\text { conselhos. }\end{array}$ \\
\hline Pestana, Vargas, Cunha ${ }^{(19)}$ & 2007 & $\begin{array}{l}\text { Discutir as contradições surgidas no } \\
\text { processo de tomada de decisões do referido } \\
\text { conselho gestor e analisar a atuação desse } \\
\text { conselho na resolução dos impasses e } \\
\text { problemas daquela comunidade. }\end{array}$ & $\begin{array}{l}\text { O conselho gestor da Unidade Básica } \\
\text { de Saúde (UBS) não representava uma } \\
\text { possibilidade efetiva de participação } \\
\text { popular, englobando impasses } \\
\text { e problemas de ordem política, } \\
\text { econômica, social e cultural. }\end{array}$ \\
\hline $\begin{array}{l}\text { Camargo-Borges, } \\
\text { Mishima }^{(20)}\end{array}$ & 2009 & $\begin{array}{l}\text { Tratar da participação social como recurso } \\
\text { fundamental para a sustentação da atenção } \\
\text { básica no SUS. }\end{array}$ & $\begin{array}{l}\text { O estudo revelou a existência de } \\
\text { vínculos entre comunidade e unidade } \\
\text { de saúde emergindo um espaço de } \\
\text { articulação e escuta entre as partes. }\end{array}$ \\
\hline Carlos et al. ${ }^{(21)}$ & 2009 & $\begin{array}{l}\text { Identificar as contradições existentes no } \\
\text { processo de escolha dos programas de } \\
\text { saúde oferecidos nas Unidades de Saúde } \\
\text { da Família. }\end{array}$ & $\begin{array}{l}\text { A população não é chamada a opinar } \\
\text { sobre os serviços oferecidos na } \\
\text { Unidade Saúde da Família (USF), fato } \\
\text { que pode dificultar o conhecimento } \\
\text { das reais necessidades de saúde da }\end{array}$ \\
\hline Soratto, Witt, Faria ${ }^{(22)}$ & 2010 & $\begin{array}{l}\text { Construir um processo de participação } \\
\text { popular e controle social em saúde, no } \\
\text { território de uma Estratégia Saúde da } \\
\text { Família. }\end{array}$ & $\begin{array}{l}\text { A construção de espaços participativos, } \\
\text { por si só, não garante a participação } \\
\text { da população e o controle social. } \\
\text { Este estudo trouxe o diálogo como } \\
\text { instrumento eficaz para fomentar e } \\
\text { buscar novos caminhos da participação. }\end{array}$ \\
\hline Longhi, Canton ${ }^{(23)}$ & 2011 & $\begin{array}{l}\text { Apresentar as contradições do conceito } \\
\text { de cidadania encontradas em pesquisas } \\
\text { realizadas junto a usuários de uma unidade } \\
\text { de saúde de São Paulo e os entraves para a } \\
\text { participação popular no SUS. }\end{array}$ & $\begin{array}{l}\text { A participação popular emerge como } \\
\text { um movimento coletivo em busca de } \\
\text { soluções para os problemas. }\end{array}$ \\
\hline Ribeiro, Nascimento ${ }^{(24)}$ & 2011 & $\begin{array}{l}\text { Compreender } \\
\text { representação } \\
\text { cocial dignificado dos sujeitos } \\
\text { construção de conselhos locais de saúde } \\
\text { (CLS) e discutir os entraves, conquistas e } \\
\text { possibilidades para um conselho efetivo. }\end{array}$ & $\begin{array}{l}\text { Houve distanciamento entre a } \\
\text { legislação e a prática do controle social } \\
\text { no processo de trabalho das equipes de } \\
\text { saúde em Feira de Santana-BA. }\end{array}$ \\
\hline Bispo-Júnior, Martins ${ }^{(25)}$ & 2012 & $\begin{array}{l}\text { Analisar o desempenho dos CLS enquanto } \\
\text { instrumentos da participação social no } \\
\text { âmbito da ESF. }\end{array}$ & $\begin{array}{l}\text { O principal entrave para o desempenho } \\
\text { dos conselhos locais é o baixo interesse } \\
\text { da população. Embora ocorra o apoio } \\
\text { da gestão, este não é suficiente para } \\
\text { promover a mobilização social. }\end{array}$ \\
\hline Martins, Santos ${ }^{(26)}$ & 2012 & $\begin{array}{l}\text { Identificar o posicionamento do } \\
\text { enfermeiro sobre sua atuação no CLS. }\end{array}$ & $\begin{array}{l}\text { Considera-se importante a atuação dos } \\
\text { enfermeiros como conselheiros uma } \\
\text { vez que houve melhorias das condições } \\
\text { de saúde da comunidade e dos serviços } \\
\text { prestados pela unidade básica. }\end{array}$ \\
\hline $\begin{array}{l}\text { Quintanilha, Sodré, } \\
\text { Dalbello-Araujo }{ }^{27)}\end{array}$ & 2013 & $\begin{array}{l}\text { Mapear os movimentos de participação } \\
\text { rizomática que emergem das ações dos } \\
\text { usuários no cotidiano de seis Unidades de } \\
\text { Saúde do Município de Vitória, ES. }\end{array}$ & $\begin{array}{l}\text { A participação rizomática se } \\
\text { caracteriza como movimentos que } \\
\text { criam, inventam e produzem novos } \\
\text { modos de existência, não restringindo } \\
\text { somente a conselhos e conferências de } \\
\text { saúde. }\end{array}$ \\
\hline
\end{tabular}




\begin{tabular}{|c|c|c|c|}
\hline Busana et al. ${ }^{(28)}$ & 2015 & $\begin{array}{l}\text { Analisar os limites e potencialidades da } \\
\text { participação popular nos CLS, por meio } \\
\text { do Itinerário de Pesquisa de Paulo Freire. }\end{array}$ & $\begin{array}{l}\text { Há necessidade de compreensão dos } \\
\text { papéis dos conselheiros e dos conselhos } \\
\text { locais de saúde para o fortalecimento } \\
\text { da promoção à saúde. }\end{array}$ \\
\hline Lima, Galimbertti ${ }^{(29)}$ & 2016 & $\begin{array}{l}\text { Analisar os sentidos da participação social } \\
\text { na saúde para lideranças comunitárias e } \\
\text { profissionais da ESF do território de Vila } \\
\text { União em Sobral, Ceará. }\end{array}$ & $\begin{array}{l}\text { A participação comunitária foi } \\
\text { primordial para a construção do SUS, } \\
\text { entretanto, é necessário uma reflexão } \\
\text { sobre a incorporação dos debates } \\
\text { em saúde nas práticas cotidianas da } \\
\text { Estratégia de Saúde da Família (ESF). }\end{array}$ \\
\hline $\begin{array}{l}\text { Pessoto, Nascimento, } \\
\text { Heimann }^{(31)}\end{array}$ & 2001 & $\begin{array}{l}\text { Esclarecer como a gestão descentralizada } \\
\text { dos serviços de saúde conduziu à adoção } \\
\text { de estruturas e práticas voltadas para } \\
\text { a da participação da comunidade na } \\
\text { administração da de saúde. }\end{array}$ & $\begin{array}{l}\text { O campo da participação popular é } \\
\text { vasto e têm-se ampliado em razão } \\
\text { do aumento do número de conselhos } \\
\text { de saúde e pela qualificação dos } \\
\text { conselheiros. }\end{array}$ \\
\hline Oliveira $^{(32)}$ & 2004 & $\begin{array}{l}\text { Entender de que maneira diferentes atores } \\
\text { sociais presentes nos conselhos de saúde } \\
\text { agem e interagem. }\end{array}$ & $\begin{array}{l}\text { Constatou-se a necessidade e a } \\
\text { importância da efetivação das } \\
\text { informações, políticas, processos } \\
\text { e recursos de comunicação pelos } \\
\text { conselhos, preferencialmente } \\
\text { dialógicos, para o exercício } \\
\text { democrático do controle social e da } \\
\text { participação popular no SUS. }\end{array}$ \\
\hline $\begin{array}{l}\text { Morita, Guimarães, } \\
\text { Muzio }^{(33)}\end{array}$ & 2006 & $\begin{array}{l}\text { Analisar a participação dos segmentos } \\
\text { que compõem o Conselho Municipal de } \\
\text { Saúde de Botucatu, e, especificamente, a } \\
\text { representatividade dos conselheiros. }\end{array}$ & $\begin{array}{l}\text { Os conselheiros mais ativos } \\
\text { reconhecem o conselho municipal } \\
\text { de saúde como uma entidade sólida, } \\
\text { integrada à administração do SUS. }\end{array}$ \\
\hline Erdmann et al. ${ }^{\left({ }^{34)}\right.}$ & 2008 & $\begin{array}{l}\text { Ampliar informações, estimulando o } \\
\text { espírito crítico/reflexivo dos usuários } \\
\text { do SUS sobre significado de cidadania } \\
\text { construído a partir da Carta dos Direitos } \\
\text { dos Usuários da Saúde e do conceito de } \\
\text { participação popular. }\end{array}$ & $\begin{array}{l}\text { Para o fortalecimento da cidadania, } \\
\text { necessita-se de um processo de } \\
\text { inclusão da participação. }\end{array}$ \\
\hline Martins et al. ${ }^{(35)}$ & 2008 & $\begin{array}{l}\text { Discutir os principais dilemas que estão } \\
\text { postos na questão da participação social } \\
\text { no Brasil. }\end{array}$ & $\begin{array}{l}\text { Há o desafio à construção da cidadania } \\
\text { exigindo ampla participação da } \\
\text { população em projetos comuns, onde } \\
\text { diversos atores sociais assumem } \\
\text { responsabilidades. }\end{array}$ \\
\hline Cotta et al. ${ }^{(36)}$ & 2010 & $\begin{array}{l}\text { Capacitar os conselheiros do município } \\
\text { de Viçosa-MG, visando a sensibilizá-los } \\
\text { para o exercício pleno e consciente de seu } \\
\text { papel no controle social. }\end{array}$ & $\begin{array}{l}\text { Em oficinas de capacitação para } \\
\text { conselheiros de saúde, focou-se na } \\
\text { sensibilização para ultrapassar a } \\
\text { posição de expectadores passivos para } \\
\text { protagonistas na construção de um } \\
\text { sistema de saúde universal e equitativo. }\end{array}$ \\
\hline Batista, Melo ${ }^{(37)}$ & 2011 & $\begin{array}{l}\text { Entender como diferentes atores } \\
\text { conseguiram absorver e garantir à } \\
\text { comunidade o direito de participar na } \\
\text { tomada de decisão em política pública de } \\
\text { saúde. }\end{array}$ & $\begin{array}{l}\text { Reconhece-se uma importante história } \\
\text { democrática no município de Ipatinga- } \\
\text { MG, tendo como marco a criação do } \\
\text { conselho de saúde. }\end{array}$ \\
\hline Cotta et al. ${ }^{(38)}$ & 2011 & $\begin{array}{l}\text { Analisar a experiência do controle social, } \\
\text { via conselho de saúde, em um município } \\
\text { de pequeno porte. }\end{array}$ & $\begin{array}{l}\text { Para os autores, a gestão participativa } \\
\text { no SUS não se consolidou como uma } \\
\text { prática efetiva. }\end{array}$ \\
\hline
\end{tabular}




\begin{tabular}{|c|c|c|c|}
\hline Severo, $\operatorname{Ros}^{(39)}$ & 2012 & $\begin{array}{l}\text { Apreender a concepção dos integrantes } \\
\text { do Coletivo Nacional de Saúde do MST } \\
\text { sobre a participação no controle social } \\
\text { do SUS e discutir as estratégias adotadas } \\
\text { nessa direção. }\end{array}$ & $\begin{array}{l}\text { Fazer o controle social não significa } \\
\text { necessariamente envolver nas esferas } \\
\text { institucionalizadas de participação, } \\
\text { mas, sobretudo, fazer a luta política } \\
\text { fora do âmbito do Estado. }\end{array}$ \\
\hline Souza et al. ${ }^{(40)}$ & 2012 & $\begin{array}{l}\text { Analisar o perfil dos conselheiros de } \\
\text { saúde do Município de Jequié e identificar } \\
\text { o conhecimento dos conselheiros acerca } \\
\text { de sua função. }\end{array}$ & $\begin{array}{l}\text { Ao atuar como conselheiro, o sujeito } \\
\text { contribui para o desenvolvimento } \\
\text { dos serviços de saúde, consolidação e } \\
\text { melhoria dos SUS. Há necessidade de } \\
\text { intensificar ações de capacitação. }\end{array}$ \\
\hline Rocha et al. ${ }^{(41)}$ & 2013 & $\begin{array}{l}\text { Analisar o conhecimento de conselheiros } \\
\text { de saúde sobre os seus papéis na } \\
\text { fiscalização do orçamento público. }\end{array}$ & $\begin{array}{l}\text { Os conselheiros fizeram menção dos } \\
\text { seus papéis no acompanhamento e } \\
\text { na avaliação do orçamento para um } \\
\text { adequado destino dos recursos à saúde. }\end{array}$ \\
\hline Silva, Pedroso, Zucchi ${ }^{(42)}$ & 2013 & $\begin{array}{l}\text { Analisar o papel da ouvidoria e sua } \\
\text { contribuição para a gestão da saúde } \\
\text { pública segundo usuários do SUS e } \\
\text { conselheiros. }\end{array}$ & $\begin{array}{l}\text { A ouvidoria de saúde é um canal que } \\
\text { amplia a voz dos usuários e assegura } \\
\text { o direito de opinar sobre as políticas } \\
\text { públicas, sendo um importante } \\
\text { instrumento de controle social. }\end{array}$ \\
\hline Barbosa et al. ${ }^{(43)}$ & 2015 & $\begin{array}{l}\text { Sistematizar a experiência de educação } \\
\text { popular. }\end{array}$ & $\begin{array}{l}\text { O fórum permanente de educação } \\
\text { popular em saúde é um espaço } \\
\text { aberto capaz de promover o diálogo, } \\
\text { empoderamento e o saber coletivo. }\end{array}$ \\
\hline
\end{tabular}

A análise de conteúdo na vertente temática ${ }^{(12)}$ desvelou duas categorias relativas à participação comunitária no SUS: "A participação comunitária na Atenção Primária à Saúde" e "Os diferentes caminhos da participação comunitária".

\section{DISCUSSÃO}

\section{A participação comunitária na Atenção Primária à Saúde}

Esta categoria teve forte representação da participação comunitária relacionada aos conselhos locais de saúde (CLSs), contribuindo com 15 artigos que discutiram o processo participativo em seus diferentes cenários e contextos, como as Unidades de Saúde da Família (USFs) e os programas de controle de endemias ${ }^{(15-29)}$.

As USFs são consideradas microespaços favoráveis à participação devido sua proximidade com a população e consequente abertura à criação de vínculos entre profissionais de saúde e usuários, o que facilita a discussão das demandas encontradas na comunidade ${ }^{(15,18-24,28)}$. Por outro lado, outro estudo ${ }^{(30)}$ discute a proximidade da USF com a comunidade como fator desencadeante de ações de vandalismo por ausência do sentimento de pertença de alguns usuários, já que, para eles, a USF pode representar a presença indesejada do Estado em dado território.

Nessa perspectiva, destaca-se a dificuldade da comunidade em se reconhecer como "parte" da construção das políticas de saúde, questão por vezes dificultada pelo modo como foram desigualmente estruturados os serviços de saúde ao longo da história, fragilizando a promoção da autonomia ${ }^{(29)}$, de maneira que estratégias de mobilização de recursos individuais e comunitários devem estimular a autonomia dos indivíduos e comunidades com o objetivo de fortalecer fatores promotores e protetores de saúde ${ }^{(9)}$.

$\mathrm{Na}$ Teoria da Democracia Participativa, de Rousseau, observa-se que a relação das instituições com seus usuários pode ou não favorecer a participação, sendo os conselhos de saúde um bom exemplo de espaço para que tal ocorra( ${ }^{(13,14)}$.

Os CLSs, criados no território das USFs, mostram-se como instrumentos institucionalizados favoráveis à participação, já que profissionais e usuários têm como propósito discutir e definir as demandas locais de saúde e as formas de intervenção, envolvendo a comunidade ${ }^{(19,24-26,28)}$.

Entretanto, alguns trabalhos apontam adversidades nos conselhos locais, como a desarticulação entre as classes, desconhecimento das responsabilidades dos papéis, dificuldade de lidar com computador e internet, falta de resolutividade das ações e níveis incipientes de envolvimento comunitário, visto que muitas demandas não tiveram a atenção necessária por parte dos gestores e do conselho municipal, causando decadência e desinteresse dos usuários nesse espaço de participação ${ }^{(19,23,25,28)}$. 
A experiência do indivíduo na tomada de decisões para que seu empenho em participar seja efetivo é muito importante. Como resultado de sua participação na tomada de decisões, o sujeito é ensinado a distinguir entre seus próprios desejos, aprendendo a ser um cidadão que pertence à comunidade, sendo os CLSs lócus privilegiado para tal exercício ${ }^{(14)}$.

Para tanto, é preciso que os conselheiros representantes da sociedade civil organizada se identifiquem com demandas da saúde e se interessem pela defesa do bem coletivo, e não na busca de benefícios individuais e imediatos, para que não seja apenas uma participação simbólica, aprovando ações programáticas propostas pela gestão sem a devida reflexão( ${ }^{(15-19,21,24,25,28)}$.

$\mathrm{Na}$ mesma direção, vários estudos ${ }^{(15,17-19,22,24)}$ destacaram a importância da população ser reconhecida como foco principal no processo participativo, assim como seu status de ator social, que detém conhecimento próprio da realidade em que atua, para que mudanças satisfatórias aconteçam. Apontam ainda que a diversidade de saberes e a criatividade da população tem como aliada a educação popular, pois é importante estratégia para a ampliação do acesso às informações em saúde e para ações de controle de endemias por meio de mudanças no comportamento dos indivíduos ${ }^{(15-17)}$.

Outro artigo destaca nova forma de participação, chamada rizomática, sendo entendida como movimentos de resistência que fabricam, inovam, descobrem novos modos de existência. Não há uma configuração preestabelecida de ocorrência desses movimentos, eles ocorrem no cotidiano do serviço, e os usuários desempenham um importante papel de vocalizar os seus desejos, demonstrarem o que querem e esperam da gestão ${ }^{(29)}$.

Mediante as diferentes formas apresentadas de participação, destaca-se que a prática cotidiana da cidadania materializa a saúde como direito universal e é ferramenta de controle das políticas públicas ${ }^{(15,20,21)}$. Entretanto, deve-se considerar que meios institucionalizados de participação em saúde não garantem a cidadania ${ }^{(15,21,24,25,27)}$. Neste caso, sugere-se que uma situação ideal seria a não existência de grupos organizados, mas apenas indivíduos, já que indivíduos não organizados estariam unidos por um ideal comum, enquanto grupos organizados podem ter interesses particulares ${ }^{(14)}$.

Caso contrário, recomenda-se que, em situações em que seja inevitável a organização de tais indivíduos, exista o maior número possível de grupos ou associações pautados no princípio de que interesses particulares sejam perdidos em prol dos interesses coletivos ${ }^{(13,14)}$. No caso da participação comunitária no SUS, esses grupos se assemelham aos conselhos locais das unidades de saúde, às associações de moradores e aos equipamentos sociais contidos nos territórios de saúde.

Por fim, a cidadania quando entendida como uma ação exercida com responsabilidade, de forma individual, social e política, pode resultar em um processo participativo. É neste momento que o cidadão percebe que seus interesses individuais e coletivos são interligados e aprende a ser um cidadão, tanto público quanto privado ${ }^{(13,14)}$.

\section{Os diferentes caminhos da participação comunitária}

A participação comunitária é uma ferramenta de controle social, pois a população pode intervir na construção do SUS, formulando, executando e avaliando as políticas públicas de saúde. Portanto, o controle da população em relação ao Estado é uma estratégia para garantir o direito à saúde e construir uma sociedade democrática ${ }^{(31-43)}$.

Esse cenário pode ser discutido na Teoria da Democracia Participativa, que considera a participação e seu controle conceitos que possuem estreito vínculo e acrescenta sua correlação com a liberdade do indivíduo ${ }^{(13)}$.

Essa via de participação e controle, no caso da saúde, pode ser entendida como os conselhos de saúde - principais órgãos de controle social na esfera municipal, tendo desdobramento estadual e nacional, considerando os princípios e diretrizes do SUS e as disposições da Lei $\mathrm{n}^{\mathrm{o}} 8.142 / 90^{(31,35,38,40,41)}$.

Os Conselhos Municipais de Saúde (CMSs) são considerados espaços recentes, onde a redemocratização se faz presente e tem sido foco de discussões a partir da década de 1970 e especialmente após o fim da ditadura militar no Brasil ${ }^{(31)}$. Desde então, a população vem buscando vias de participação e outras formas de controle social além dos conselhos de saúde, como associações de profissionais de saúde ou usuários, ouvidorias públicas em saúde, Ministério Público, entre outras instâncias ${ }^{(32,42)}$.

Uma sociedade participativa é capaz de operar modificações sobre os indivíduos, que podem ser positivas ou negativas ${ }^{(14)}$, sendo que ações ou intervenções, quando são individuais, devem estar de acordo com as leis que levam em consideração a vontade geral. Sendo assim, existem normas que regulam e limitam aquilo que os cidadãos podem ou devem fazer - o controle $^{(44)}$.

As ouvidorias públicas em saúde são um bom exemplo e têm como função monitorar o funcionamento da administração pública, sendo importante para apurar reclamações, denúncias e fiscalizar as políticas de saúde ${ }^{(42)}$.

Um estudo ${ }^{(39)}$ destaca a concepção do Movimento dos Trabalhadores Rurais Sem Terra sobre a participação no controle social do SUS, revelando outra forma de controle social: a luta política através de estratégias de ocupação, de mobilizações e de marchas, e não necessariamente por meio da presença em conselhos e conferências de saúde.

Nesse sentido, há evidencias da representatividade de conselheiros associados a sindicatos, principalmente ligados à saúde do trabalhador e de trabalhadores portadores de problemas relacionados ao trabalho ${ }^{(33)}$.

Em relação aos avanços dessa representação, classificando-a fora dos moldes democráticos ideais, como destacado por alguns estudos ${ }^{(33,35)}$, os quais evidenciam a pouca participação dos usuários do SUS em debates durante encontros e/ou reuniões 
de conselhos. Embora sempre estivessem presentes, apenas acompanhavam as discussões e votavam no momento em que eram solicitados, sem questionar decisões.

Para tanto, deve-se considerar que a composição dos conselhos prevê a heterogeneidade e composição paritária dos usuários, sendo compostos por " $50 \%$ de entidades de usuários; $25 \%$ de entidades dos trabalhadores de saúde; $25 \%$ de representação de governo, de prestadores de serviços privados conveniados, ou sem fins lucrativos" ${ }^{\text {(45), }}$, sendo um forte instrumento de controle social.

Apesar de prevista a paridade, nota-se que apenas os conselheiros mais ativos reconhecem a importância de seu papel como cidadãos e do conselho de saúde para o município, podendo analisar criticamente os avanços e resultados alcançados ${ }^{(33,35)}$.

Por outro lado, não se pode desconsiderar que uma parcela da população brasileira é marginalizada e excluída e tem seus direitos negados, permanecendo sob doação de cidadania pelo Estado quando conveniente. Exemplo disso acontece em alguns municípios, onde a paridade é desrespeitada e sofrem forte influência político-partidárias ${ }^{(38,40)}$. Importante ressaltar que, muitas vezes, a população tem pouco conhecimento da existência dos conselhos e, desse modo, desconhece o quanto pode apoderar-se por meio de um conselho realmente ativo $^{(40)}$.

Para que esta realidade seja modificada e haja a efetivação do controle social, é necessário aos conselheiros o reconhecimento de seu papel e sua capacitação quanto às bases legais e ideológicas sobre a participação proposta pelo SUS ${ }^{(36)}$. Dessa forma, questões reflexivas devem ser levantadas em relação à cidadania e aos direitos coletivos na saúde.

O conselheiro de saúde deve cumprir o compromisso de articular-se com diferentes atores, participar de debates e discussões frequentes, divulgar os resultados das reuniões mensais para a população e fiscalizar as políticas públicas ${ }^{(34-36,40,41)}$.

Intrinsecamente relacionado às noções de controle e liberdade, encontra-se a função educativa como item central na participação da comunidade: "Como resultado de sua participação na tomada de decisões, o indivíduo é ensinado a distinguir entre seus próprios impulsos e desejos, aprendendo a ser tanto um cidadão público quanto privado"(13).

Neste caminho, pode se relacionar à função educativa da participação o empoderamento dos indivíduos ou comunidades acerca da tomada de decisões referentes à saúde ${ }^{(35)}$, tendo como apoio recomendações da Política Nacional de Promoção da Saúde, que estimula a capacitação de lideranças e formadores de opinião ${ }^{(9)}$.

O empoderamento tem similaridade com o termo "libertação", usado por Paulo Freire, isto é, os cidadãos adquirem liberdade de uma situação socialmente excludente por meio da educação, vista como fator predisponente para que o indivíduo reconheça e busque a prática participativa e de controle social ${ }^{(35,38,46)}$.

Acredita-se que a educação para o controle social e o SUS devem estar integradas a uma política que estimule a transmissão de informações, tendo como atores os profissionais dos serviços, universidades, gestores da saúde e comunidade ${ }^{(43)}$. Assim, a educação popular é uma ferramenta aliada na construção do SUS, pois caracteriza-se como um espaço aberto à comunidade, capaz de promover o diálogo, compartilhar experiências e construir um saber coletivo ${ }^{(43)}$.

Depreende-se, finalmente, que o controle social tem função deliberativa na participação em saúde, com espaços amparados pela legislação vigente. Os conselhos e outros espaços participativos podem ser encontrados em diferentes lócus de tempo e espaço, concretizados como importantes instâncias ao afetar diretamente as políticas públicas de saúde no Brasil.

\section{CONCLUSÃO}

O presente estudo deu visibilidade à produção científica acerca da participação comunitária no SUS e pode-se inferir que apresentou crescente incorporação na prática cotidiana dos conselheiros locais e municipais no campo da saúde coletiva. Revelou diferentes olhares sobre essa prática no que se refere aos conselhos de saúde e aos diferentes modos de participação, tanto na atenção primária como em outras instâncias, com o re-despertar do interesse dos cidadãos.

Portanto, é um campo de pesquisa que se encontra em aberto e necessita de reflexões nos seus diversos cenários, com foco nas práticas educativas sobre as bases legais e ideológicas da participação comunitária.

\section{REFERENCIAS}

1. Serapioni M, Antunes P, Ferreira PL. Participação em saúde: conceitos e conteúdos [paper]. Sesimbra; 2010.

2. Paim JS. Ações integradas de saúde (AIS): por que não dois passos atrás. Cad Saúde Pública. 1986;2(2):167-83.

3. Escola Politécnica de Saúde Joaquim Venâncio. Dicionário da educação profissional em saúde: Sistema Único de Saúde [Internet]. Rio de Janeiro: Fiocruz; 2009 [acesso em 2015 Abr 21]. Disponível em: http://www.sites.epsjv.fiocruz.br/ dicionario/index.html

4. Cohn A. Políticas de saúde e reforma sanitária hoje: delimitações e possibilidades. Ciênc Saúde Coletiva. 2008;13(Supl 2):2021-3. 
5. Brasil. Constituição (1988). Constituição da República Federativa do Brasil. Brasília: Senado Federal; 1988.

6. Brasil. Lei n. 8.080, de 19 de setembro de 1990. Dispõe sobre as condições para a promoção, proteção e recuperação da saúde, a organização e o funcionamento dos serviços correspondentes e dá outras providências. Diário Oficial da União, 20 set 1990 .

7. Brasil. Lei n. 8.142, de 28 de dezembro de 1990. Dispõe sobre a participação da comunidade na gestão do Sistema Único de Saúde (SUS) e sobre as transferências intergovernamentais de recursos financeiros na área da saúde e dá outras providências. Diário Oficial da União, 28 dez 1990.

8. Cabral MV. O exercício da cidadania política em perspectiva histórica (Portugal e Brasil). Rev Bras Ciênc Soc. 2003;18(51):31-60.

9. Ministério da Saúde (BR). Política Nacional de Promoção da Saúde: documento para discussão. Brasília: Ministério da Saúde; 2002.

10. Teixeira ML, Vianna W. Participação em saúde: do que estamos falando? Sociologias. 2009;11(21):218-51.

11. Ganong LH. Integrative reviews of nursing research. Res Nurs Health. 1987;10(1):1-11.

12. Bardin L. Análise de conteúdo. Lisboa: Edição 70; 2011.

13. Pateman C. Participação e teoria democrática. Rio de Janeiro: Paz e Terra; 1992.

14. Rousseau J-J. Discurso sobre a economia política e do contrato social. Petrópolis: Vozes; 1995.

15. Fernandes JCL, Monteiro JGC. Postos comunitários: uma alternativa para o sistema de saúde. Cad Saúde Pública. 1997;13(1):127-35.

16. Coura-Filho P. Participação popular no controle da esquistossomose através do Sistema Único. Cad Saúde Pública. 1988; 14(Supl 2):111-22.

17. Vàzques ML, Silva MRF, Campos ES, Arruda IKG, Diniz AS, Veras IL, et al. Participação social nos serviços de saúde: concepções dos usuários e líderes comunitários em dois municípios do Nordeste do Brasil. Cad Saúde Pública. 2003;19(2):579-91.

18. Arantes CIS, Mesquita CC, Machado MLT, Ogata MN. O controle social no Sistema Único de Saúde: concepções e ações de enfermeiras da atenção básica. Texto \& Contexto Enferm. 2007;16(3):470-8.

19. Pestana CLS, Vargas LA, Cunha FTS. Contradições surgidas no Conselho Gestor da Unidade Básica de Saúde da Família de Vargem Grande, Município de Teresópolis-RJ. Physis (Rio de J). 2007;17(3):485-99.

20. Camargo-Borges C, Mishima SM. A responsabilidade relacional como ferramenta útil para a participação comunitária na atenção básica. Saúde Soc. 2009;18(1):29-41.

21. Carlos EF, Silva CC, Silva ATMC, Braga JEF. Programa de Saúde da Família: Inclusão dos Usuários na Escolha dos Serviços Oferecidos. Rev Bras Ciênc Saúde. 2009;13(2):63-8.

22. Soratto J, Witt RR, Faria EM. Participação popular e controle social em saúde: desafios da Estratégia Saúde da Família. Physis (Rio de J). 2010;20(4):1227-43.

23. Longhi JC, Canton GAM. Reflexões sobre cidadania e os entraves para a participação popular no SUS. Physis (Rio de J). 2011;21(1):15-30.

24. Ribeiro FB, Nascimento MAA. Exercício de cidadania nos conselhos locais de saúde: a (re)significação do 'ser sujeito'. Rev Baiana Saúde Pública. 2011;35(Supl 1):151-66.

25. Bispo-Júnior JP, Martins PC. Envolvimento comunitário na estratégia de saúde da família: dilemas entre institucionalização e efetiva participação. Physis (Rio de J). 2012;22(4):1313-32.

26. Martins ALX, Santos SMR. O Exercício do controle social no Sistema Único de Saúde: a ótica do enfermeiro como membro do Conselho Local de Saúde. Saúde Soc. 2012; 21(Supl 1):199-209.

27. Quintanilha BC, Sodré F, Dalbello-Araujo M. Movimentos de resistência no Sistema Único de Saúde (SUS): a participação rizomática. Interface Comun Saúde Educ. 2013;17(46):561-73.

28. Busana JM, Heidemann ITSB, Wendhausen ALP. Participação popular em um conselho local de saúde: limites e potencialidades. Texto \& Contexto Enferm. 2015;24(2):442-9. 
29. Lima FA, Galimbertti PA. Sentidos da participação social na saúde para lideranças comunitárias e profissionais da Estratégia Saúde da Família do território de Vila União, em Sobral-CE. Physis (Rio de J). 2016;26(1):157-75.

30. Botti ML, Scochi MJ. O aprender organizacional: relato de experiência em uma unidade básica de saúde. Saúde Soc. 2006;15(1):107-14.

31. Pessoto UC, Nascimento PR, Heimann LS. A gestão semiplena e a participação popular na administração da saúde. Cad Saúde Pública. 2001;17(1):89-97.

32. Oliveira VC. Comunicação, informação e participação popular nos conselhos de saúde. Saúde Soc. 2004;13(2):56-69.

33. Morita I, Guimarães JFC, Di Muzio BP. A participação de conselheiros municipais de saúde: solução que se transformou em problema. Saúde Soc. 2006;15(1):49-57.

34. Erdmann AL, Backes DS, Klock P, Koerich MS, Rodrigues CRL, Drago LC. Discutindo o significado de cidadania a partir dos direitos dos usuários da Saúde. Rev Enferm UERJ. 2008;16(4):477-81.

35. Martins PC, Cotta RMM, Mendes FF, Franceschinni SCC, Priore SE, Dias G, et al. Conselhos de saúde e a participação social no Brasil: matizes da utopia. Physis (Rio de J). 2008;18(1):105-21.

36. Cotta RMM, Cazal MM, Rodrigues JFC, Gomes KO, Junqueira TS. Controle social no Sistema Único de Saúde: subsídios para construção de competências dos conselheiros de saúde. Physis (Rio de J). 2010; 20(3):853-72.

37. Batista EC, Melo EM. A participação popular em Ipatinga (MG, Brasil): conquistas e desafios do setor saúde. Ciênc Saúde Coletiva. 2011;16(1):337-47.

38. Cotta RMM, Martins PC, Batista RS, Franceschinni SCC, Priore SE, Mendes FF. O controle social em cena: refletindo sobre a participação popular no contexto dos conselhos de saúde. Physis (Rio de J). 2011;21(3):1121-38.

39. Severo DO, Ros MA. A Participação no Controle social do SUS: concepção dos Movimento dos Trabalhadores Rurais Sem Terra. Saúde Soc. 2012;21(Supl 1):177-84.

40. Souza TO, Silva JM, Nóbrega SS, Constâncio JF. Controle Social: um desafio para o Conselheiro de Saúde. Rev Bras Enferm. 2012;65(2):215-21.

41. Rocha EM, Cunha JXP, Lira LSSP, Oliveira LB, Nery AA, Vilela ABA, et al. O papel do conselheiro municipal de saúde na fiscalização do orçamento público. Saúde Debate. 2013;37(96):104-11.

42. Silva RCC, Pedroso MC, Zucchi P. Ouvidorias públicas de saúde: estudo de caso em ouvidoria municipal de saúde. Rev Saúde Pública. 2014;48(1):134-41.

43. Barbosa AM, Silva JNF, Araújo EKG, Pereira JC, Lacerda DAL, Alvarenga JPO. Fórum permanente de educação popular em saúde: construindo estratégias de diálogos e participação popular. Rev APS. 2015;18(4):554-9.

44. Vilalba HG. O contrato social de Jean-Jacques Rousseau: uma análise para além dos conceitos. Filogênese [Internet]. 2013 [acesso em 2015 Abr 21];6(2):63-76. Disponível em: http://www.marilia.unesp.br/filogenese/

45. Conselho Nacional de Saúde (BR). Resolução n. 333, de 4 de novembro de 2003. Aprova as diretrizes para criação, reformulação, estruturação e funcionamento dos Conselhos de Saúde. Diário Oficial da União, Brasília, 4 dez 2003.

46. Freire P. Pedagogia da autonomia: saberes necessários à prática educativa. São Paulo: Paz e Terra; 1996.

\section{Endereço para correspondência:}

Violeta Campolina Fernandes

AC Rubião Júnior, Jardim Santo Inácio (Rubião Júnior)

CEP: 18618-970 - Botucatu - SP - Brasil

E-mail: vicampolina@gmail.com 